\title{
Innovations and Analysis of Textile Digital Printing Technology
}

\author{
Ali Ugur Koseoglu ", Yusuf Gungor, Yucel Devrim Arık \\ Menderes Design Center, Menderes Textile Co. Denizli, Turkey \\ Email address: \\ aliugurkoseoglu@menderes.com (A. U. Koseoglu) \\ ${ }^{*}$ Corresponding author \\ To cite this article: \\ Ali Ugur Koseoglu, Yusuf Gungor, Yucel Devrim Arık. Innovations and Analysis of Textile Digital Printing Technology. International Journal \\ of Science, Technology and Society. Vol. 7, No. 2, 2019, pp. 38-43. doi: 10.11648/j.ijsts.20190702.12
}

Received: April 10, 2019; Accepted: June 19, 2019; Published: June 29, 2019

\begin{abstract}
This paper reports the evaluation of textile digital printing including our experimental observations in production and this paper encloses the analysis of innovations and unease features of digital printing industry also. Digital printing can make apperal and home textile pattern design more attractive. However, the application of digital printing contains some constrains. Also the application of traditional printing contains some constrains. Technology rapidly improves today so those improvements better the digital printing everyday. These improvements are not yet complete. At this stage, it may be difficult for investors to decide. Sufficient knowledge and experience is needed to invest in digital printing technology. You can obtain this support through counseling and research methods. After sufficient knowledge and feasibility studies, digital printing technology can be invested. Our article evaluates digital printing technology from a wide angle thus we aim to help those who do research on the subject. Digital printing machines have a complex structure. Many disciplines such as electronics, mechanics, chemistry, textiles, fashion and art are intertwined for digital textile printing technology. It is not possible to have all disciplines in one person. Efficient operation of the digital printing machine can only be achieved with a strong team. First of all, you need pattern work designers and equipments capable of feeding digital printing with their work. In the next stage, you will need people to do the calibrations and color work. If you add more, machine operator, electronic and mechanical team, fabric pre and post treatment team, logistic support people will be needed. The size of the team depends on the size of the work. The most problematic parts of digital printing machines are the printheads where the dye is sent to the fabric surface. New developments are taking place every day in this regard.
\end{abstract}

Keywords: Digital Printing, Textile, Inkjet Printing, Textile Printing, Apperal Design

\section{Introduction}

This work aims to show a way for a wider perspective for textile digital printing technology. Traditional screen printing has several limiting layers such as poor registration of the design, stains, pinholes, colour correctness, colour consistency, colour smear, dye migration, scorching, improper curing, etc. These restriction layers adversely affect the overall outcome of prints. There are several significant benefits to digital printing, most notably, savings in time and space, faster print speeds and the ability to print with both reactive inks, which are used with fabrics like wool, cotton and silk, and disperse inks, which must be used with polyester. Most notable benefit capability to dispense both types of inks from the same machine is that the changeover time between inks is only 10 minutes, compared to 120 minutes associated with traditional printing [1-13].

The product design process consists of three dimensions of aesthetics, functionality, and symbolism. Aesthetic phenomenon refers to the perception of beauty or physical appearance of a product. Functionality refers to the basic functionality of a product and/or a product's intended purpose. In the same way, the symbolism focuses on certain meanings or signs that informing status, self-image, and/or social roles on the basis of visual components. Product design was recognized as one of the leading determinants of the competitive advantage and performance determinants of companies. Recognizing that superior design can notice products by creating and communicating value to customers, thus increasing customer acquisition and retention, both brand 
managers and design researchers emphasized the importance of product design and attributed superior design to new product success. Therefore, product design significantly influences a product's consumer assessment. Different and not ordinary designs always create interest. To overcome some attractive difficult pattern designs is possible by digital printing [2].

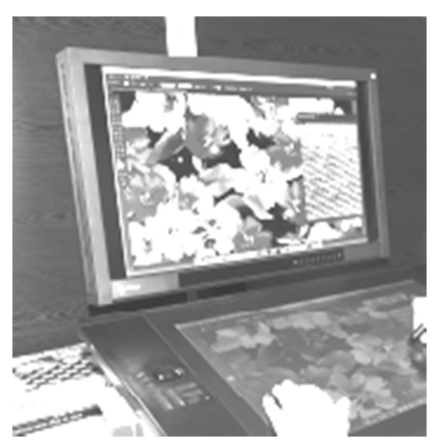

(a)

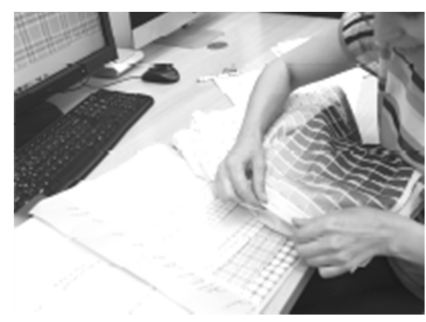

(b)

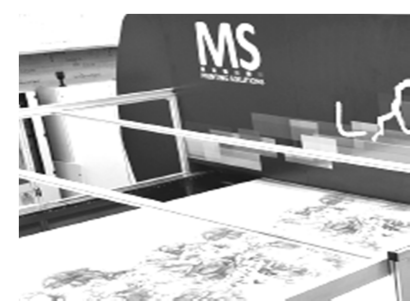

(c)

Figure 1. Pattern design, colouring and digital prnting respectively.

\section{Methods}

With the digital printing machines we use in our factory, we have real observation and testing capabilities. Special designs have been choosen for our study; these designs have too small repeat sizes, too high resolutions, too thin lines, complicated geometrical patterns, soft halftone patterns, too much colour numbers and photographic patterns. Printing process has been done at MS JP-6, MS JP-7, MS JPK EVO, MS LARIO, REGGIANI, RENOUR digital printing machines. One of these digital machine is single pass type and the others scanner type. You can see digital machine types at table 1 [3]. Some of obtained results are: Ability to print designs at high resolutions up to $1200 \mathrm{dpi}$. This means two-three times more resolution than conventional printing. Ability to print too thin lines down to 20-30 micron. Between 0 and 256 levels density differences are used by graphic design programs for half tone colours. To obtain $90 \%$ of these levels by digital printing is possible. This ratio is $40 \%-50 \%$ for conventionel printing. No colour registration problem, excellent dimentional accuracy. Faster, easier and cheaper design improvement/revision process. More designs and more colour variants can be achived in a shorter time period. Possibility of printing small fine details, excellent softness of half tone designs and there is no colour number limitation. More luxuriant and aesthetic patterned apperal designs can be achived with digital printing.

One of the important factors of shaping apperal style is colours and patterns of apperals. The purpose of us is to develop the aesthetic quality to the highest level. To overcome some difficult pattern designs is possible by dijital printing. We have created our pattern design samples by using graphic design programs of Adobe Photoshop, Adobe Illustrator, Ramsete, Corel Draw.

Table 1. Digital Textile Printing Machine Types [3].

\begin{tabular}{|c|c|c|}
\hline Machine Type & Segment Describtion & Target Aplications \\
\hline \multirow{3}{*}{$\begin{array}{l}\text { Plotter } \\
\text { (Class 1-2) }\end{array}$} & $4-30 \mathrm{~m} / \mathrm{h}$ & \multirow{3}{*}{$\begin{array}{l}\text { Sampling, } \\
\text { transfer print, } \\
\text { soft signage small lots } \\
\text { for any kind of printed } \\
\text { fabric product }\end{array}$} \\
\hline & $30-100 \mathrm{~m} / \mathrm{h}$ & \\
\hline & Plotter based & \\
\hline \multirow{2}{*}{$\begin{array}{l}\text { Scanner } \\
\text { (Class 3) }\end{array}$} & $\begin{array}{l}100-400 \mathrm{~m} / \mathrm{h} \text {, } \\
\text { industrial }\end{array}$ & \multirow{2}{*}{$\begin{array}{l}\text { Sampling, small to } \\
\text { medium lots } \\
\text { production, mainly apperal, } \\
\text { hometex (large width) but also } \\
\text { signage }\end{array}$} \\
\hline & production $25-200 \mathrm{~m} / \mathrm{h}$ & \\
\hline $\begin{array}{l}\text { Single Pass } \\
\text { (Clas } 4)\end{array}$ & $\begin{array}{l}20-70 \mathrm{~m} / \mathrm{min} \text {. } \\
\text { Printing unit fixed } \\
\text { position } \\
\text { Nonstop moving } \\
\text { substrate } \\
\text { Intagrated drying unit }\end{array}$ & $\begin{array}{l}\text { Traditional rotary screen } \\
\text { products, but also small to } \\
\text { medium apperal and hometex } \\
\text { products, large print lots in short } \\
\text { delivery times, transfer print. }\end{array}$ \\
\hline
\end{tabular}

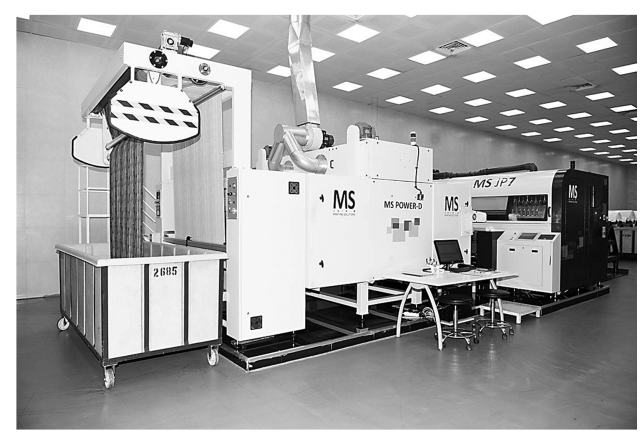

Figure 2. Scanner class textile digital printing machine.

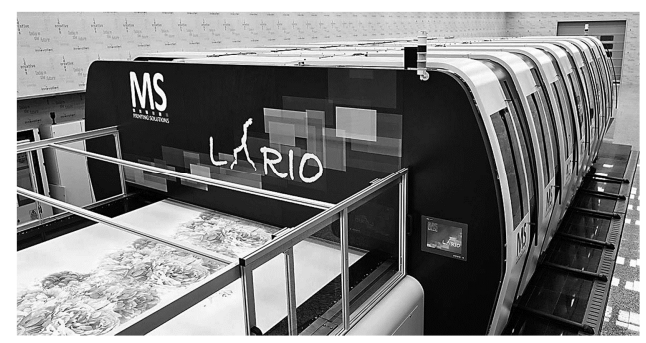

Figure 3. Single pass class textile digital printing machine.

Effective digital textile printing still wants for an industrial environment with require to wet- and dry finishing equipment 
for the pre- and post-treatment. Processes cannot yet be standardized because of treatments depend on type of substrates, type of inks, print penetration and type use of the final product. The consideration of a proper pre- and post-treatment and its effect on the print quality is often depends on involved parties.
The reliability of print heads is one of the main demands of future developments in digital textile printing. Machine manufacturers know this issue and partially offer support to customers to share risk of inability. You can see important print-head brands main features at table 2.

Table 2. Digital Textile Printing Print-Heads [3].

\begin{tabular}{llll}
\hline Product & Main Features & & Remarks \\
\hline & Resolution (native) & $600 \mathrm{dpi}$ & Current market leader in terms of \\
& $(2$ colours) & $300 \mathrm{dpi}$ & quantities (offers diffrent models, also \\
with 2 or 4 channels)
\end{tabular}

At the present day, Kyocera is the most widely-used print head for scanner and single pass type digital textile printing machines. For none of the print-head provider, digital textile printing is the real purpose of their business activities. The most widely-used print head provider is changing rapidly in every new generation of print head served for digital textile printing.

Print heads are considered the most important part of the digital textile printing machine. The performance of a digital textile printing machine is directly proportional to the number of print heads working on the machine. The life span of the print head is related to the quality of the ink used in the machine, the electronic design of the machine and the physical-mechanical design of the print head. If one of the most suitable inks is used, life span of print heads is changing between one and two years at the present day thus maintenance and spare parts costs are reduced. The print quality of a print head is changing over its lifetime what challenges the print lot allocation to machines in a digital textile printing facility [3].

\section{Result and Discussion}

The advantages of digital textile printing are huge and can have a huge impact on the textile market as a whole. At the present day, the most challenging component of mass textile printing is design. Digital printing provides higher color definition with short designing time which is not possible with conventional printing. In addition, production can be done in lower quantity orders with lower investment cost. The cost is reduced by less capital, less materials, less fabrics and less ink. An important development seen by environmentalists, consumers and producers is that there is a significant decrease in electricity and water consumption in digital textile printing. It can be said that over $30 \%$ savings on electricity costs and almost $95 \%$ in terms of water consumption. Another advantage is the reduction in inventory costs, as the customer's low demands can be met easily. In particular, this provide a great advantage in the fashion industry for the small collections of designers and a limited edition fabrics which require high-quality printing [4].

The manufacture, dissemination and improvement of digital textile printing technology is in line with the development of software and hardware technology and is inseparable from each other. These developments do not only directly affect the production process but also indirectly affect people's creative thinking skills. Although digital textile printing technology consists of complex elements, it allows for the application of highly demanding, complex, excellent pattern designs. It makes the pattern design more original. However, compared to conventional printing, digital textile printing technology still has a lot to improve [5]. The widespread use of digital 
textile printing depends on the ability of the technology to increase production speed and decrease the cost of paint. Advances in technology, innovations in paint and other consumables, developments in the printheads and machine mechanisms are crucial for digital printing [6].

The spread of online digital printing services is one of the new creative economic initiatives. Desktop publishing became widespread and easy for individual designers and many designers from large-scale fashion design companies to freelance designers took advantage of this service. The technology could not be directed very quickly to digital printing with suitable dyes in fabrics. Today's modern designers use digital pattern design and digital textile printing to further design aesthetics. Moreover small-scale designers make their own unique designs and print short run fabrics by using Adobe Photoshop or Microsoft Paint on their home computers through online digital textile services. [7].

Developments in the digital home textile printing market are at the target center of digital textile printing machine manufacturers and ink producing companies for these machines. Producing print heads that can be operated faster, producing inks with higher light fastness, decrease the cost of fabric square meters to more convenient levels are the primary destinations of those companies. The home textile digital print market needs to be developed for increasing the overall digital textile market development, and also vat dye inks and pigment inks needs to be developed for this sector. In the recent days, the use of pigment ink in digital textile printing has been significantly improved and pigment inks are used in scanning digital printing applications. Unhappily, single pass digital textile machines do not give enough sureness to users and they still need acceptable print head performance. Developed print head systems that operate at high production speeds are still needed [8].

There is a significant variation between pigment ink and reactive ink which is printed on woven cotton fabrics. This knowledge is very useful for fashion design students, textile design programs as well as professional industrial designers. Due to the rapid growth in the digital textile printing sector, it has always been necessary to conduct new scientific research. New ink types, fiber technologies, and printing equipment are permanently developed. Continuous quality assurance research should be carried out in order to find the compatible inks in different fibers and productions in the digital textile printing industry. For example, customers expect the colors in athletic wear to not bleed or stain during perspiration and children's wear to withstand multiple launderings. This research was aimed to help small businesses with digital textile printing fabric and ink choices for the proper colorfastness. Choosing to use an inconvenient fabric with specific ink can unfavorable affect a company's business. There are some studies that will help companies and customers better choose cotton fabrics and printing ink processes more appropriate for their purposes [9].

Digital inkjet printing is a production technology with high potency in resource efficient processes, which characterizes both flexibility and productivity. The physical and chemical features of the ink such as surface tension, non-newtonian features and particle size are very critical. The variations in construction of the textile together with ink filament interaction attribute to the various transportation behaviors of the ink on the textile, reflected in the durability of the functional layer on the textile. The functionalized textile preserves its important textile properties such as softness and breathability. Textile inkjet printing technology shows huge potential in high end applications such as customized functionalization of textiles in the extent of smart textiles [10].

It is possible to find the optimum conditions for digital textile printing processing with using Taguchi Method. In a study named as "Optimization of Digital Textile Printing

Process using Taguchi Method" [11] color strength and wash fastness were chosen as characteristic values and two kinds of multiple-characteristic value analyses were performed to find the conditions that satisfy both criteria.

One of the most important features of textile inkjet printing technology is that for many textile substrates such as polyester, silk, nylon and cotton can be printed. One of them, namely polyester fiber has a high crystalline, compact, and hydrophobic formation. This formation makes polyester one of the most important materials for digital printing. Home textiles have many applications such as upholsteries, sheets, draperies, carpets, covers, and curtens in consequence of polyester has many special properties such as excellent behavior during exploitation, resilience, and superior strength and uniform quality.

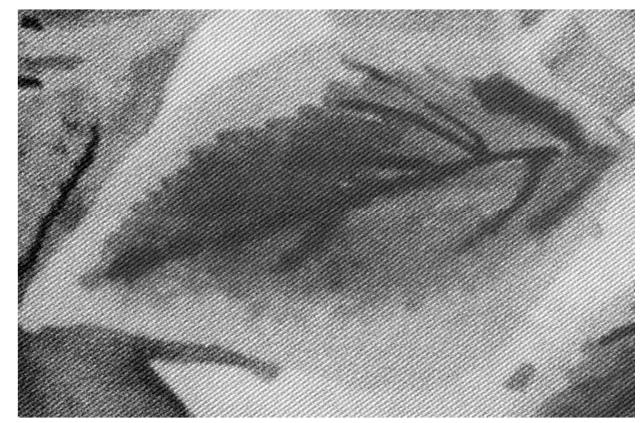

Figure 4. Digital printed leaf pattern on cotton fabric. It is possible to see very clear and soft pattern. (scale $2 x$ ).

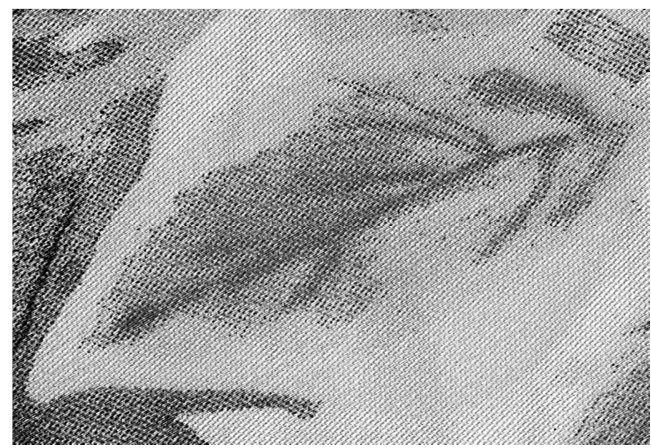

Figure 5. Traditional screen printed leaf pattern on cotton fabric. Pattern is not clear and details are lost. (scale $2 x)$.

Dispers inks and pigment inks can be used for polyester substrate inkjet printing. Disperse inks are used in the transfer 
and direct printing technologies. In transfer printing, the designed patterns are printed onto a special paper by disperse dyes, which are able to sublimation. Subsequently the dehydrated pattern is transferred from paper to substrate by a sublimation process or steaming. The prepared pattern can be inkjet printed onto a prepared polyester substrate in the direct printing technology. For achieving direct printing, pretreatment with a thickener is needed to control dye absorbing. Unfortunately, in addition to the advantageous conditions described above, digital textile printing also has some weaknesses. These weak conditions; the spread of ink and low color gamut. In digital textile printing, print quality is mostly due to the structure of the substrate and the interaction of the ink with the substrate. The interaction between ink and paper in paper digital printing has been well researched so far. However, the interaction between textile substrate and ink in textile digital printing has not been sufficiently researched. If you compare with the paper substrates, the textile substrates have relatively a rough surface; thus, the obtaining of high quality prints is more trouble. Some researchers have studied the factors affecting the quality of inkjet textile printing. Exemplary, Liao et al., He examined the last steps of pre-treatment on the quality of cotton substrate. The effects of sodium alginate concentration and steaming on pattern clarity were examined. It was found that the concentration of sodium alginate increased the quality of the pattern. Liu et al. [12] in the preatreatment stage, they studied sodium alginate with different solution derivatives with fatty acid. The aim of the study was to find the affect of solution derivatives on the ink drop spreading. They found that the spreading area of cyan ink drops was decreased. What are the factors affecting the print quality of textile inkjet printing and what are the tools for quantifying print quality? The obtained results show that the print quality of the fabric is influenced by the fabric structure, yarn size, and the hydrophilic/hydrophobic nature of the fabric. The other result is the quality of digital textile printing on plain weave and knitted cotton fabric is affected by the fabric pretreatments [14].

The saturation and gamut of the colors were greatly enhanced by the products developed for commercially available pigment-based dyeing fabric pretreatments. In this way, there has been great development of fabric surface energy. The pre-treatment range for polyester effectively expanded and gave stronger colors. For both substrates, the colour gamut increased not only along the L direction (Lab color space), but also along a (Lab color space) and b (Lab color space) directions, which indicates attaining colours with higher chroma. The comparison of pre-treated cotton and polyester fabrics shows that the colors are more vivid in cotton and have a appreciably larger color gamut. This difference is due to the fact that pretreated cotton has more surface energy. A lot of work is done on the basis of the improvement of the crockfastness with the pretreatments in both polyester and cotton fabrics, these studies are the primary subjects of the circles working on pigment based textile digital printing. Pretreatment proccess increases pigment levels on the fabric surface. Key step of advances in crockfastness will only be by understanding the physical state of the pigment particles in the binder layer on pre-treated or non-pre-treatment fabrics [15].

In addition to encounter new challenges to meet the needs of the market, digital printing technology is improving fastly. These can be summarized as; heads, ease of technology, nozzles, personel training, cost and pigment inks.

Cost: The biggest obstacle to the further development of the digital printing method is the cost problem, compared to other printing techniques used, other techniques are generally cheaper. However, digital textile printing technology offers very attractive facilities to the market demanding high-quality and expensive products. The closest example is the flat bed printing method, compared with digital printing, the cost of paint and chemicals in digital printing is 3-4 times higher, everyday this cost is getting lower levels. The initial investment cost is also very high for dijital printing. However, in the near future, the cost is going to come down and replaceable parts become more affordable. This advantage will be doubled with the increase in digital printing speed, perhaps changing places with the rotation printing machines in the near future. With the cost of ink in digital printing, the cost of print heads is also very high. Therefore, the development of long-lasting, durable print heads will cut costs down.

Ease of technology: In recent years, although much progress has been made in the ease of technology, other traditional methods are still easier. For single-pass machines, smudges and trace defects in gray tones and solid colours should still be improved. The size of the print heads should be optimized and their hardwares developed. In-depth studies should be done in pigment digital printing technique. In this way, a revolution will be made in pigment printing with $85 \%$ share in total production. Pigment inks are undergoing a very detailed research and development process. Other possibilities could be a advancement of a block polymer of polyurethane and acrylate.

Nozzles: Nozzles must be modified for smooth flow of pigment particles, otherwise nozzles are clogged. Nozzles modification is a more important change than diminishing the size of pigment particles, if not the printing aesthetic is compromised. Reducing the size of the pigment particles to less than 1 micron results in a decrease in print color yield and a decrease in vividness in the pattern. If pigment chemistry and nozzle engineering are considered at the same time, success is achieved. Solvent auxiliary chemicals will soon become very important for pigment inks.

Personel Training: Maintenance and repair of the machines and equipment play a very important role, otherwise it will be very difficult to operate the machine. In order to cope with this difficulty, there is a need for personnel who understand many mechanisms of the machine and can find analytical solutions to problems [16].

\section{Conclusion}

Nowadays, the most rapidly developing subject of textile machinery is digital textile printing. Digital textile printing, which is still unable to eliminate the cost discretion against 
traditional printing, has superiority at very different points except cost. These superiority points are such as speed to market, design flexibility and new business models. The inclusion of digital textile printing in the market in the coming periods will also bring down costs. As a result, digital textile printing will increase its share in total printing.

Some of our benefits thanks to digital printing: No colour registration problem, excellent dimentional accuracy. Faster, easier and cheaper design improvement/revision process. More designs and more colour variants can be achived in a shorter time period. Possibility of printing small fine details, excellent softness of half tone designs and there is no colour number limitation. More luxuriant and aesthetic patterned apperal and home textile designs can be achived with digital printing.

The reliability of print heads is one of the main demands of future developments in digital textile printing. Machine manufacturers know this issue and partially offer support to customers to share risk of inability. Print heads are considered the most important part of the digital textile printing machine. The performance of a digital textile printing machine is directly proportional to the number of print heads working on the machine. The life span of the print head is related to the quality of the ink used in the machine, the electronic design of the machine and the physical-mechanical design of the print head. Unhappily, single pass digital textile machines do not give enough sureness to users and they still need acceptable print head performance.

An important development seen by environmentalists, consumers and producers is that there is a significant decrease in electricity and water consumption in digital textile printing. It can be said that over $30 \%$ savings on electricity costs and almost $95 \%$ in terms of water consumption.

\section{References}

[1] Charles K. Ntim, Sophia P. Ocran and Richard Acquaye (2017). Digital Textile Printing: A New Alternative to Short-Run Textile Pirinting in Ghana. International Journal of Technology and Management Research Vol. 2, No. 1: 60-65.

[2] Naeem Gul Gilal, Jing Zhang and Faheem Gul Gilal. (2018) Linking product design to consumer behavior: the moderating role of consumption experience. Journal of Psychology Research and Behavior Management 2018; 11: 169-185.

[3] Jos Notermans (June 27, 2018) SpgPrints Group. Gherzi Paper Digital Textile Printing, July 7, 2018 https://blog.spgprints.com
[4] Guy Evron. March 29, 2016. Is the Textile Digital Printing Revolution Just Around the Corner? March 1, 2018 https://www.industrialprintblog.com

[5] Yanli Hu. ICSNCE 2016. The influence of modern digital design on traditional tie-dye. Jiangxi Garment Collage, School of Management, Nanchang, Jiangxi.

[6] Noor Ahmed Memon. (2018) Rapidly changing fashion trends growth in the textile printing market. Pakistan Textile Journal, April 2018, 66-67.

[7] Plummer, Brianna; Sanders, Eulanda A.; and Baytar, Fatma, "The Rise of Online Digital Textile Printing Services and its Impact on Costume Design Practice" (2017). International Textile and Apparel Association (ITAA) Annual Conference Proceedings. 181 https://lib.dr.iastate.edu/itaa_proceedings/2017/posters/181

[8] John Provost. (2018) Weighing Up Development Opportunities Journal of Digital Textile, Issue 8: 2018, 23-24.

[9] Thompson, Katherine L., "Digital textile printing: colorfastness of reactive inks versus pigment inks" (2016). Graduate Theses and Dissertations. 15186. https://lib.dr.iastate.edu/etd/15186.

[10] Junchun Yu, Sina Seipel, Vincent A. Nierstrasz. Digital inkjet functionalization of water-repellent textile for smart textile application. Journal of Materials Science, 2018, Volume 53, Number 18, Page 13216.

[11] Jin Joo Jung, Sungmin Kim, Chang Kyu Park (2016). Optimization of digital textile printing process using Taguchi Method. Journal of Engineered Fibers and Fabrics 11, Issue 2.

[12] Z. Liu, K. Fong, H. Gao, K. Liu and J. Zhang, Color. Technol 132, 407 (2016).

[13] MS Printing Solutions. Case Study: Living the Digital Dream. October 5, 2016 www.msitaly.com

[14] Abbas Hajipour and Ali Shams-Nateri (2017). The Effect of Fabric Density on the Quality of Digital Printing on Polyester. Journal of Fibers and Polimers Vol. 18, No. 12, 2462-2468.

[15] Yi Ding, Renzo Shamey, Lisa Parillo Chapman and Harold S. Freeman (2018). Pretreatment effect on pigment-based textile inkjet printing-colour gamut and crockfastness properties. Journal of Coloration Technology, Socety of Dyers and Colourist, 135, 77-76.

[16] Muhammad Aslam Khan. Textile Consultant (2018). Challenges faced by digital printing industry. Pakistan Textile Journal-November 2018, 48-50.

[17] Figures. Menderes Textile Photo Archive. 